\title{
LUTAS URBANAS NO CAIS MAUÁ E NA AVENIDA PAULISTA: METODOLOGIA QUALITATIVA PARA COMPREENSÃO DE TRANSFORMAÇÕES NO ESPAÇO PÚBLICO DAS CIDADES
}

\author{
URBAN DISPUTES AT CAIS MAUÁ AND AVENIDA PAULISTA: QUALITATIVE \\ METHODOLOGY FOR UNDERSTANDING TRANSFORMATIONS IN PUBLIC SPACES OF \\ CITIES
}

Sérgio Carvalho Benício de MELLO¹, Antônio Fagner da Silva BASTOS², Carlos César de Oliveira LACERDA³.

Palavras-chave: Teoria do discurso; Políticas públicas; Lutas urbanas; Transformações urbanas:

Cidades.

Keywords: Discourse theory; Public policy; Urban struggles; Urban transformations; Cities.

\section{RE S U M O}

As cidades estão em constante transformação. Mudanças que afetam direta ou indiretamente a vida de seus habitantes. Estes, cientes ou não, atuam para moldar o ambiente urbano conforme suas preferências. Assim, partindo do pressuposto que a construção da realidade metropolitana se dá através das disputas políticas entre os atores citadinos, 0 artigo tem 0 objetivo de propor um delineamento metodológico para análise de transformações urbanas com base na Teoria do Discurso de Laclau e Mouffe, visando apontar diretrizes que possam guiar novos trabalhos, de cunho qualitativo, que busquem estudar transformações nas cidades e como estas se deram por meio de construções discursivas de grupos conflitantes. A metodologia proposta colabora para o entendimento de como uma política pública, um movimento social ou uma organização informal é capaz de modificar uma condição posta já hegemonizada. São usados dois exemplos ilustrativos, em São Paulo e no Rio Grande do Sul, de como a metodologia foi aplicada para se estudar lutas políticas urbanas.

\section{A B S T R A C T}

Cities are constantly changing. Changes that directly or indirectly affect the lives of its inhabitants. These, aware or not, act to shape the urban environment according to their preferences. Thus, based on the assumption that the construction of the metropolitan reality occurs through political disputes between city actors, this paper proposes a methodological design for the analysis of urban transformations based on the Theory of Discourse by Laclau and Mouffe, pointing to guidelines that can lead to new works, of a qualitative nature, that seek to study transformations in cities and how they came about through discursive constructions by conflicting groups. The proposed methodology contributes to the understanding of how a public policy, a social movement or an informal organization is capable of modifying an already hegemonized condition. Two illustrative examples are used, in São Paulo and Rio Grande do Sul, of how the methodology was applied to study urban political struggles.

\footnotetext{
1 Doutor em Business Studies pela University of London, Inglaterra (1999). Professor Titular da Universidade Federal de Pernambuco. E-mail: sergio.benicio@gmail.com.

2 Doutorando em Administração pelo Programa de Pós-Graduação em Administração da Universidade Federal de Pernambuco. E-mail: fagnersbastos@gmail.com.

${ }^{3}$ Doutorando pelo Programa de Pós-Graduação em Administração da Universidade Estadual do Ceará. E-mail: cesarlacerda.adm@hotmail.com.
} 


\section{INTRODUÇÃO}

A cidade é um ente em permanente transformação. Um prédio pode ser utilizado para determinado fim e no ano seguinte demolido para atender outro interesse. Uma avenida pode ter sua largura redefinida para dar mais ou menos espaços para o deslocamento de veículos, bem como ter seu uso alterado por períodos distintos. Um espaço público abandonado pode ter fins diversos, como ser cedido à iniciativa privada, ser transformado em uma praça pública. A paisagem urbana se formará a partir de regras previamente estabelecidas ou se moldará sem um controle específico. A construção de uma escola em determinado bairro poderá revigorar aquele lugar, assim como a implementação de um megaempreendimento imobiliário gerará efeitos na região, como o aumento do trânsito em certos horários. Assim, as grandes cidades passam por constantes modificações.

No entanto, como para cada ação há uma reação, cada decisão exemplificada acima, haverá beneficiados e prejudicados, e, em virtude disso, grupos atuando por seus interesses. Frente ao contexto de constantes mudanças, no qual as cidades vão se modelando e remodelando, torna-se necessária a compreensão de como as transformações urbanas são possivveis. Diante dessa necessidade, o seguinte questionamento se faz premente: como a realidade é alterada no contexto das cidades? Partimos de um pressuposto onto-epistemológico que a realidade, ao menos em ambientes democráticos, se constrói discursivamente através da dimensão política. Em outras palavras, são os atores que constroem suas realidades por meio de seus discursos sobre o que é e o que não é considerado bom para eles.

Tema de interesse aos estudos da administração pública, o trabalho em tela tem o objetivo de propor um delineamento metodológico com base na Teoria do Discurso de Laclau e Mouffe (2015) para análise de transformações urbanas. A metodologia proposta colabora para o entendimento de como uma política pública, um movimento social ou uma organização informal é capaz de modificar uma condição posta já hegemonizada. A escolha da teoria se dá porque no campo da administração, Laclau e Mouffe são geralmente utilizados em estudos de movimentos de resistência (DELAGNELLO; BÖHN; MENDONÇA, 2014). Considerando que a Aqui, pretendemos seguir em semelhante caminho e apontar diretrizes que possam guiar novos trabalhos, de cunho qualitativo, que visem estudar transformações nas cidades e como estas se deram por meio de construções discursivas de grupos conflitantes.

Por fim, acreditamos que pesquisadores urbanos podem se beneficiar de um modelo analítico desta natureza. $O$ arcabouço a ser apresentado discute a produção do espaço, compreendendo a atuação nele dos diferentes atores, refletindo sobre o modo de organização e articulação da sociedade civil e como seu poder coletivo pode ser transformador. 


\section{TEORIA DO DISCURSO: ALGUNS CONCEITOS}

A Teoria do Discurso de Laclau e Mouffe, apresentada em Hegemony and socialist strategy: towards a radical democratic politics no ano de 1985, é uma teoria pós-marxista e construcionista social que visa à compreensão das lutas políticas contemporâneas. É pós-marxista por buscar atualizar aquilo que o marxismo, após as crises da esquerda europeia na década de 1980, não era mais capaz de responder ao pensar o social: as lutas de classe agora são lutas hegemônicas (BASTOS; MELLO, 2017a). É construcionista por entender que tanto a realidade como as significações da sociedade são construídas por posições de sujeito precárias, contingentes e transitórias, dentro de diferentes jogos de linguagem (LACLAU; MOUFFE, 2015). Diante das abordagens voltadas à utilização e a compreensão do discurso nas ciências sociais, a Teoria do Discurso surge como uma alternativa epistemológica para o entendimento de eventos políticos, sociais e culturais (HOWARTH, 2000; HOWARTH; NORVAL; STRAVAKAKIS, 2000; MENDONÇA, 2003).

Considerando que a construção da realidade se dá através das disputas políticas, a compreensão da implementação de políticas, a Teoria do Discurso se torna um aparato teórico que investiga como as práticas sociais articulam e contestam discursos (CORDEIRO; MELLO, 2010; BASTOS; MELLO, 2017a; LACERDA; MELLO, 2018). Conforme Lopes, Mendonça e Burity (2015, p. 16-17), é uma teoria da "identificação de significantes cuja contestação ou múltiplo investimento por parte dos vários atores sociais permite construir articulações que alteram a ordem vigente". Os principais conceitos da teoria para sua melhor compreensão são: discurso, hegemonia, antagonismo social, articulação, ponto nodal, cadeias de equivalência e cadeias de diferença, elementos, momentos e deslocamento e nova hegemonia (CORDEIRO; MELLO, 2010; BASTOS; MELLO, 2017ª; LACERDA; MELLO, 2017).

A Teoria do Discurso é uma teoria que problematiza os discursos políticos. Por discurso, compreendemos não são somente as falas, mas envolve uma gama de linguagens que vai muito mais além $e$ que desvelam significados em torno dos acontecimentos, ou seja, o discurso nessa perspectiva, precisa ser entendido como um sistema de significados contingentes inerentes às estruturas sociais (CORDEIRO; MELLO, 2010; FOUCAULT, 1996).

Segundo Howarth e Stavrakakis (2000), a hegemonia deriva das articulações das diferentes identidades através de suas atividades políticas que estão inseridas em um mesmo projeto, objetivando uma nova ordem social. Assim, as hegemonias são compreendidas por meios dessas articulações e para isso ocorrer é preciso ter a existência de um antagonismo e a presença de atores com projetos políticos sobrepostos. Hegemonizar expressa anexar seu significado ao redor de um ponto nodal, onde o campo discursivo se apresenta como espaço de disputas (LACLAU; MOUFFE, 2015). 
Conforme apontado por Howarth (2000), antagonismos sociais ocorrem porque os agentes sociais são incapazes de alcançar suas identidades (seus interesses), e porque eles constroem um "inimigo" que é considerado responsável por esse fracasso. 0 antagônico é sempre um discurso exterior; é sempre, um discurso com diferente positividade (BASTOS; MELLO, 2017a). O antagonismo é entendido como a impossibilidade da constituição de um sentido objetivo, ou finalístico, de toda lógica discursiva (MENDONÇA, 2010). De acordo com Torfing (1999) o "outro" em relação ao "eu" é demonstrado por meio da negação de identidade começando uma luta pela hegemonia. A hegemonia e a exclusão provocam o surgimento de posições contrárias que também se torna um agente na busca pela posição hegemônica (BASTOS; MELLO, 2017a; LACERDA; MELLO, 2017).

A articulação pode ser definida como "qualquer prática que estabeleça uma relação entre elementos de tal modo que sua identidade seja modificada como um resultado de prática articulatória" (LACLAU; MOUFFE, 2015, p. 178). A lógica discursiva proposta por Laclau e Mouffe (2015) é o resultado de práticas articulatórias que fixam sentidos parciais por meio de pontos nodais que articulam elementos e momentos. Assim, qualquer constituição discursiva, pensada em termos de sistema discursivo, estrutura e reestrutura sentidos (MENDONÇA, 2012). Elementos são diferenças que não se apresentam articuladas por razão de caráter flutuante; momentos são posições diferenciais que aparecem articuladas em um discurso; e pontos nodais, pontos de referência em um discurso responsáveis por gerar convergência dentro de um sistema de significados (LACLAU; MOUFFE, 2015).

Quando a identidade do sujeito muda, ocorre o deslocamento. A ideia de deslocamento refere-se à possibilidade de transformações ou mudanças nas identidades dos sujeitos e em suas posições dentro da estrutura discursiva ou campo discursivo. Podem ser compreendidos como processos que tornam visíveis o caráter contingencial da arena social e política (SILVA; BATISTA; MELLO, 2014; BASTOS; MELLO, 2017a; LACERDA; MELLO, 2017).

Por meio da localização dessas categorias é possível entender a chegada e a busca de uma nova hegemonia discursiva.

\section{UM MODELO DE PESQUISA}

Com a intenção de suprir uma carência metodológica apresentada pela Teoria do Discurso, a racionalidade retrodutiva foi proposta em 2007 por Glynos e Howarth, na obra Logics of critical explanation in social and political theory. $O$ método tem como forma de apropriação investigações que envolvem problemas de pesquisa de natureza política e social, nas quais o investigador busca enunciar condições que tornaram possiveis ou seriam necessárias para a ocorrência de determinado fenômeno (OLIVEIRA; OLIVEIRA; 
MESQUITA, 2013; BATISTA; SILVA; MELLO, 2014). A retrodução difere, portanto, da indução e da dedução, como explicam Oliveira, Oliveira e Mesquita (2013).

A retrodução consiste em uma dinâmica de formulação de relações em que o processo de construção de enunciados não parte de certas condições antecedentes para concluir suas consequências como na dedução, nem parte de eventos específicos para enunciar uma regra, como na indução (OLIVEIRA; OLIVEIRA; MESQUITA, 2013, p. 1336).

Howarth et al. (2016) apresentam que a lógica da explanação crítica se divide em cinco passos relevantes: problematização, retrodução, lógicas, articulação e crítica. Entretanto, pode-se considerar que estão aglutinados em três grandes momentos, onde a problematização é responsável pelo primeiro momento, a retrodução juntamente com as lógicas e a articulação são responsáveis pelo segundo momento, formando os ciclos retrodutivos e por fim, o momento da crítica que é formando pela justificação e persuasão.

Momento 1 - Problematização: A problematização possibilita alguns questionamentos a partir da construção e interpretação do fenômeno estudado para assim, expandir o campo discursivo, envolvendo todo o fenômeno empírico (BASTOS; MELLO, 2017; LACERDA; MELLO, 2018). Não é um diagnóstico simples e se aproxima da problematização abordada por Foucault que envolve como algo é questionado (BACCHI, 2012).

Momento 2 - Retrodução, Lógicas e Articulação: A explicação retrodutiva seria a compreensão do fenômeno a partir de hipóteses melhoradas, ou seja, por ciclos retrodutivos, reinterpretando as observações levantadas na problematização (BASTOS; MELLO, 2017a; LACERDA; MELLO, 2018). Glynos e Howarth (2007) discute as práticas sociais a partir de três lógicas: a lógica social, a lógica política e a lógica fantasmática. A lógica social responde a questão "o que?" e se pauta em caracterizar as práticas definindo as regras e normas através das estratégias de normatização.

A lógica política responde a questão do "como?" que conta com a emergência histórica por meio da formação da prática se debruçando sobre os conflitos que foram o pano de fundo da constituição e a lógica fantasmática responde a questão "por quê?" e se debruça em entender a forma como os sujeitos são unidos a prática (BASTOS; MELLO, 2017a; LACERDA; MELLO, 2018). Nesta lógica se faz presente uma força motriz ideológica que motiva e movimenta sujeitos políticos. Sobre a articulação é relevante articular esses vários tipos de lógicas, conectando a pluralidade de modo a considerar o fenômeno problematizado (GLYNOS et al., 2015).

Momento 3 - Crítica: A persuasão e intervenção (explanação) é o momento conclusivo do trabalho, onde a teoria é mencionada e se traz uma argumentação a partir dos achados para convencer e propor intervenções numa literatura engajada (OLIVEIRA et al., 2013). O método é uma abordagem antipositivista, pois os discursos não são fixos e abordam problemas de pesquisa de natureza política e social (BASTOS; 
MELLO, 2017a; LACERDA; MELLO, 2018). O desenvolvimento de uma hipótese faz parte do processo, isso não significa que ela tem a intenção de ser testada, mas, sobretudo a conclusão da análise será essa mesma hipótese de forma melhorada, dessa forma, a hipótese deve produzir determinadas causas e prever os efeitos do fenômeno (GLYNOS; HOWARTH, 2007).

Segundo Oliveira e colegas (2013) ao invés de testar as hipóteses $(H)$ lançadas inicialmente, a abordagem da pesquisa passa a sugerir vários ciclos retrodutivos, rediscutindo a hipótese e aprofundando 0 conhecimento sobre o fenômeno. No que diz respeito a aplicabilidade e operacionalização na Teoria do Discurso, resumidamente, pode-se dizer que o momento da retrodução inicia-se quando um fenômeno é percebido e observado, ou seja, o fenômeno seria $(F)$. Essa observação de $F$ pode inicialmente ser explicada por $\mathrm{H}$ que depois das análises por meio dos ciclos retrodutivos, ela será ajustada de acordo com os discursos (GLYNOS; HOWARTH, 2007). Dessa maneira, a (re) elaboração faz parte do processo, de forma que 0 fenômeno seja observado por meio da articulação do agenciamento político (BASTOS; MELLO, 2017a; LACERDA; MELLO, 2018).

De maneira prática, a análise se inicia com a problematização. Para tal, algumas ações são necessárias: Identificar um antagonismo social, localizar a hegemonia que os discursos conflitantes estão inseridos, apontar as articulações existentes e como elas atuam, identificar os pontos nodais que movem as identidades, compreender as disputas e as mudanças delas oriundas. Para ilustrar nossa proposta, apresentamos 0 delineamento da Figura 1.

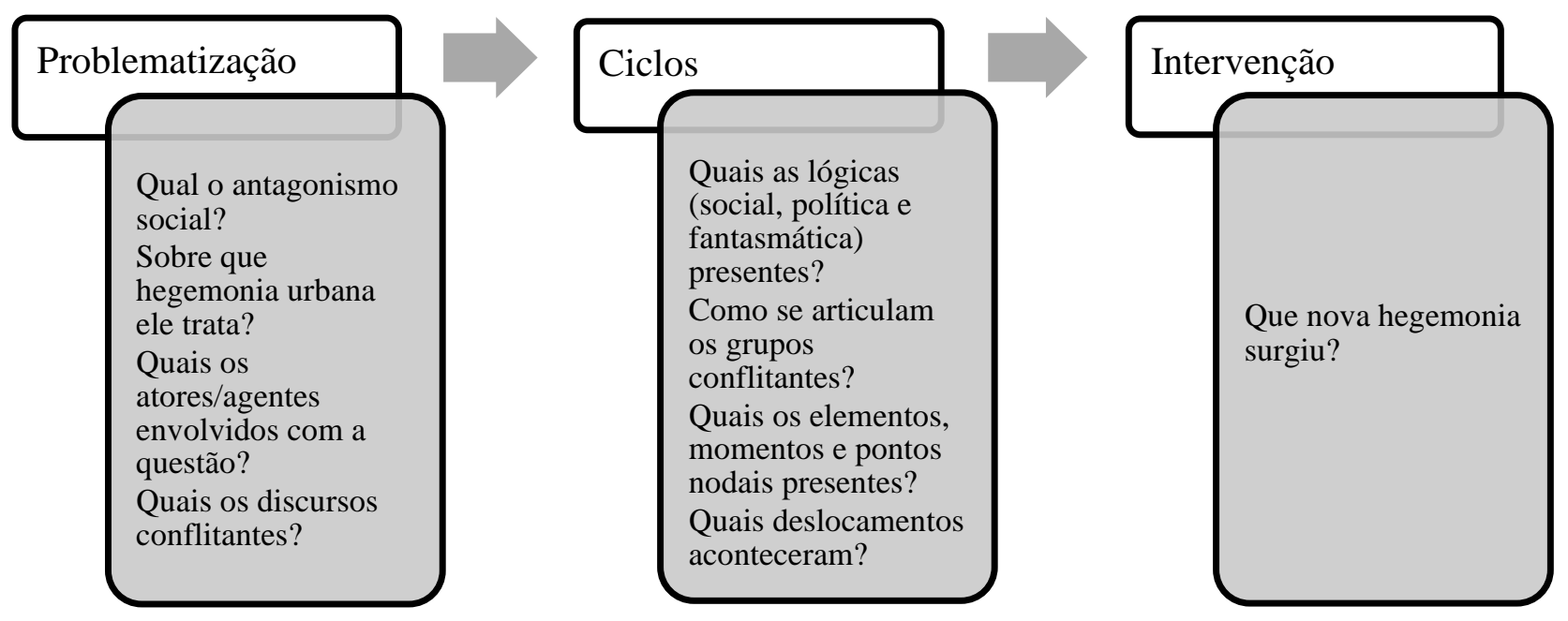

Figura 1 - Delineamento metodológico em três momentos Fonte: Elaborado pelos autores com base em GLYNOS e HOWARTH, 2007. 
A seguir, mostramos dois exemplos em que o delineamento metodológico foi utilizado. 0 primeiro trata das lutas por ressignificação no Cais Mauá em Porto Alegre/RS e o segundo sobre as disputas por diferentes grupos pelo uso da Avenida Paulista em São Paulo/SP.

\section{APLICANDO O MODELO}

Como visto anteriormente, a retrodução consiste num método para investigações sobre problemas de pesquisa de natureza política e social, onde o pesquisador busca enunciar condições de possibilidade - que tornariam possíveis ou seriam necessárias - para a existência do fenômeno estudado. 0 primeiro passo então é identificar o objeto de estudo (uma tensão urbana), os discursos que o circundam (que significados carregam) e quais atores os proferem (estes podem ser divididos em subgrupos). E assim construir um arquivo de pesquisa. Este é construído a partir das posições dos sujeitos políticos nos variados ambientes. Nesse sentido, é preciso selecionar material que represente conteúdos importantes, com profundidade e que ao mesmo tempo tenha uma diversidade de vozes nas discussões sobre as tensões urbanas estudadas. 0 arquivo vai se formando conforme avança o estudo e novos atores aparecem.

Assim, para ambos os exemplos que aqui serão apresentados foi construído um arquivo com fontes secundárias e primárias obtidas dos atores políticos envolvidos nas lutas urbanas. Ambos os casos também foram discutidos com um foco menos metodológico em trabalhos anteriores (LACERDA; MELLO, 2018; BASTOS; MELLO, 2017a). No exemplo do Cais Mauá, o arquivo foi construído com base em três subgrupos de atores: o poder público, o empreendedor e os movimentos de resistência. Do poder público, os dados foram coletados através de jornais eletrônicos por meio de reportagens; documentos como notas de repúdio, leis, ações judiciais; relatórios ambientais, notícias retiradas do site da Prefeitura, Governo do estado e do âmbito federal, canais que representaram o discurso oficial dessa categoria. Do grupo institucional referente ao empreendedor, foram matérias vinculadas no site do consórcio Cais Mauá Brasil S.A., canal que representa o discurso oficial dessa categoria. E do último grupo, os dados foram coletados em redes sociais por meio de blogs referente a sociedade civil organizada e Facebook.

Além desses dados secundários, outros primários foram coletados através de entrevistas semiestruturadas baseadas em um roteiro de pesquisa com perguntas abertas que foram subdivididas por 3 temáticas teóricas norteadoras. Em relação a temática "produção capitalista do espaço" foi elaborado 4 questões, em relação a temática "direito à cidade" também foi elaborado 4 questões e por último em relação a temática "discursos" foi elaborado 5 questões, totalizando 13 questões norteadoras no roteiro semiestruturado, o que levou a discussão de diferentes pontos durante as entrevistas. Estas foram realizadas com os representantes dos movimentos de resistência como Cais Mauá de Todos e Minha Porto Alegre, 
representantes da Associação dos Moradores do Centro Histórico, Associação Gaúcha de Proteção ao Ambiente Natural (AGAPAN), Associação dos Geógrafos de Porto Alegre (AGB) e alguns representantes do Estado, totalizando 8 entrevistas. A forma de acesso aos entrevistados foi por acessibilidade e foram coletadas no mês de outubro de 2016 na cidade de Porto Alegre. Tiveram duração em média de 40 minutos cada entrevista e foram transcritas na íntegra pelos pesquisadores. Também foi realizado observação participante por meio de visitas ao local onde está localizado o Cais Mauá. Os pesquisadores fizeram anotações de campo, registro fotográfico e participou de passeios no objeto de estudo na intenção de saber se aquele lugar seria desprovido de historicidade (LACERDA; MELLO, 2018).

Já no exemplo da Avenida Paulista, o arquivo se deu com fontes secundárias de informativos e documentos oficiais, campanhas virtuais, manifestos, posicionamentos, notas à imprensa e notícias em meios de comunicação virtuais do maior número possível de sujeitos envolvidos, num total de 102 documentos, além de observação participante. $O$ trabalho de coleta ocorreu dentro de um espaço situado entre setembro de 2013 - data da primeira notícia relacionada a tentativas de abertura da Avenida Paulista para que encontramos - e junho de 2016 - data da publicação pela Prefeitura de São Paulo de um decreto oficializando a medida. De forma complementar, como fontes primárias, foram realizadas duas entrevistas com integrantes de duas organizações governamentais envolvidas nos embates e uma com um representante de um órgão da Prefeitura. Ao todo, foram cinco fontes: o discurso do governo, representado pela Prefeitura e órgãos auxiliares; o discurso dos grupos a favor da medida, formado principalmente por organizações ativistas; o discurso mediador, identificado no Ministério Público de São Paulo; o discurso dos grupos contrários, composto por entidades da sociedade civil como ordem dos advogados do Brasil e associações de moradores da região; e por último, o discurso da mídia, que narrava os fatos que iam se sucedendo (BASTOS; MELLO, 2017a).

\subsection{Cais Mauá em Porto Alegre (RS)}

O porto Cais Mauá é um espaço com inúmeras peculiaridades e possui um turismo forte diante do cenário brasileiro. Está localizado na cidade de Porto Alegre/RS e atualmente perdeu sua função, tornando o espaço sem atividades (Figura 2). 


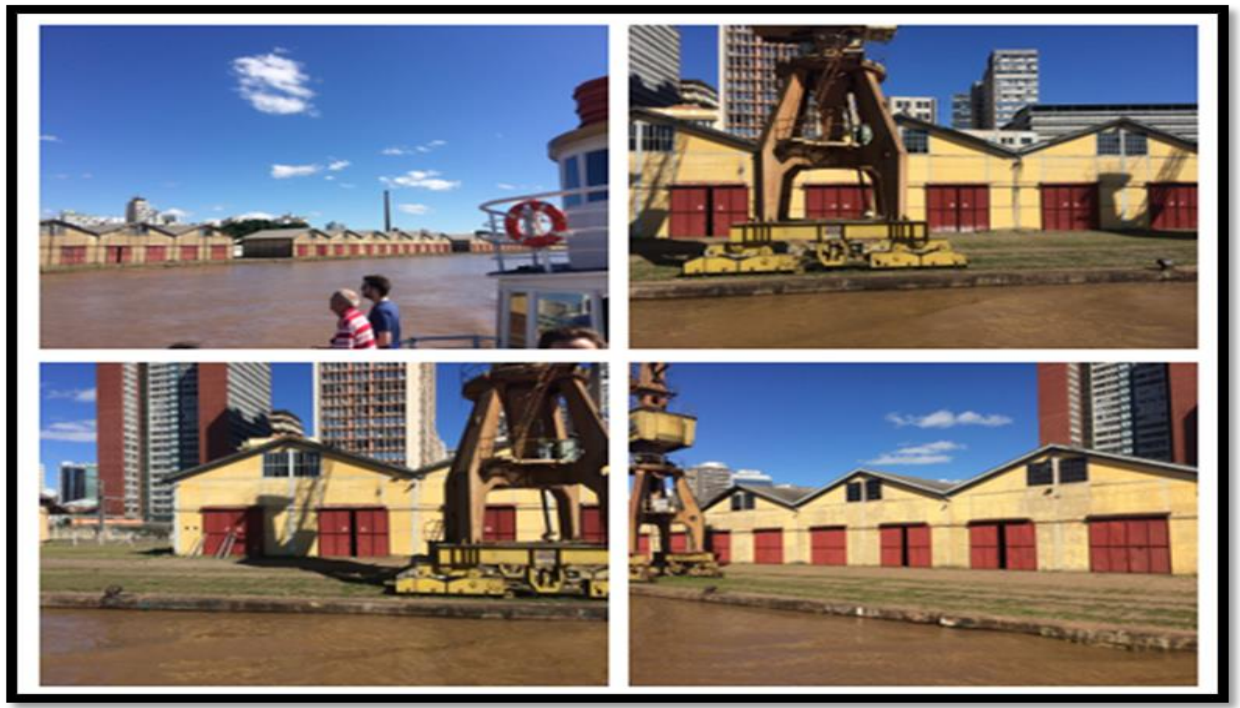

Figura 2 - 0 Cais Mauá atualmente

Fonte: Dados da pesquisa, 2016.

O porto está situado à margem esquerda do Rio Guaíba, na Av. Mauá e une o centro produtor regional com um dos maiores portos marítimos do Mercosul. O centro de Porto Alegre é conhecido por sua preservação histórica, arquitetônica e artística, que é denominado o centro histórico de Porto Alegre. Dessa forma, o Cais Mauá faz parte da história da cidade cujas características especiais o fizeram ser protegido pelos Patrimônios Histórico Nacional e Municipal (PHNM). A importância histórica do Cais Mauá reside no fato de sua construção resultar de um grande esforço conjunto entre o governo e a sociedade gaúcha, que se empenhavam, no início do século XX, para modernizar a capital e incrementar a economia (LACERDA; MELLO, 2018).

As áreas dos centros históricos com o passar dos anos foram perdendo, por diversas razões, seu valor econômico, social e cultural. Tais áreas possuem um valor simbólico e recentemente tem se percebido uma retomada desses espaços por meio de intervenções urbanísticas, requalificando a cidade e fazendo com que a sociedade passe a reutilizar o espaço. A região central de Porto Alegre onde se localiza o Cais Mauá atualmente é alvo de recuperação pelo poder privado e público para a preservação e ao mesmo tempo, o fomento ao turismo local (LACERDA, 2017).

\subsubsection{Momento 1: Problematização}

Durante alguns anos vem sendo discutidos projetos para requalificar o Cais Mauá. Após várias tentativas desses projetos, em 2010 foi lançado o Edital de Concorrência 001/2010, para aprovação das propostas de requalificação do Cais. De acordo com o edital e atendendo as diretrizes do plano diretor da 
cidade, o projeto vencedor da concorrência deve observar e priorizar a acessibilidade, o restauro do patrimônio histórico e a realocação dos prédios públicos atualmente existentes (LACERDA; MELLO, 2018). No final do referido ano foi assinado um contrato entre a Cais Mauá do Brasil S.A. e o Governo do Estado para a requalificação do Cais. "Um porto Alegre" como muitos chamaram a requalificação, apresenta como objetivos uma modificação para fins empresariais, de turismo, de lazer e cultural.

No que diz respeito ao contrato, ele é considerado um arrendamento com prazo de 25 anos, renováveis. 0 Estado receberá do consórcio o valor de $\mathrm{R} \$ 2,5$ milhões anuais pelo arrendamento. Caberá também ao Porto Cais Mauá a manutenção das obras sociais e dos 33 eventos, como a Feira do Livro, o Museu de Arte Contemporânea e a Bienal do Mercosul, e sustentar os investimentos na área ao longo dos 25 anos do arrendamento. Algumas outras iniciativas tentaram requalificar o Cais com diferentes propostas de uso do espaço público, mas que não deram certo, como por exemplo: em 1991 o projeto Caminho do Porto, em 1996 o projeto Porto dos Casais, em 2000 o projeto Complexo Cinematográfico do RS e em 2005 foi criada uma comissão de requalificação para o Cais Mauá, que inspirou o projeto atual (VIEIRA, 2012; LACERDA, 2017).

O projeto atual prevê a construção de torres comerciais, shopping center, um grande estacionamento, centro de eventos, hotel, centro empresarial e espaços voltados para negócios, consumo e comércio (Figura 3). Dessa forma, o espaço começa a ser alvo de polêmicas devido à proposta grandiosa de requalificação. Em 2015, o Cais Mauá foi objeto de discussões referentes a esse projeto por grupos que se manifestaram contra o projeto aprovado, ou seja, demonstrando que a requalificação não é uma unanimidade para a população, gerando conflitos no andamento (LACERDA; MELLO, 2017; LACERDA; MELLO, 2018).

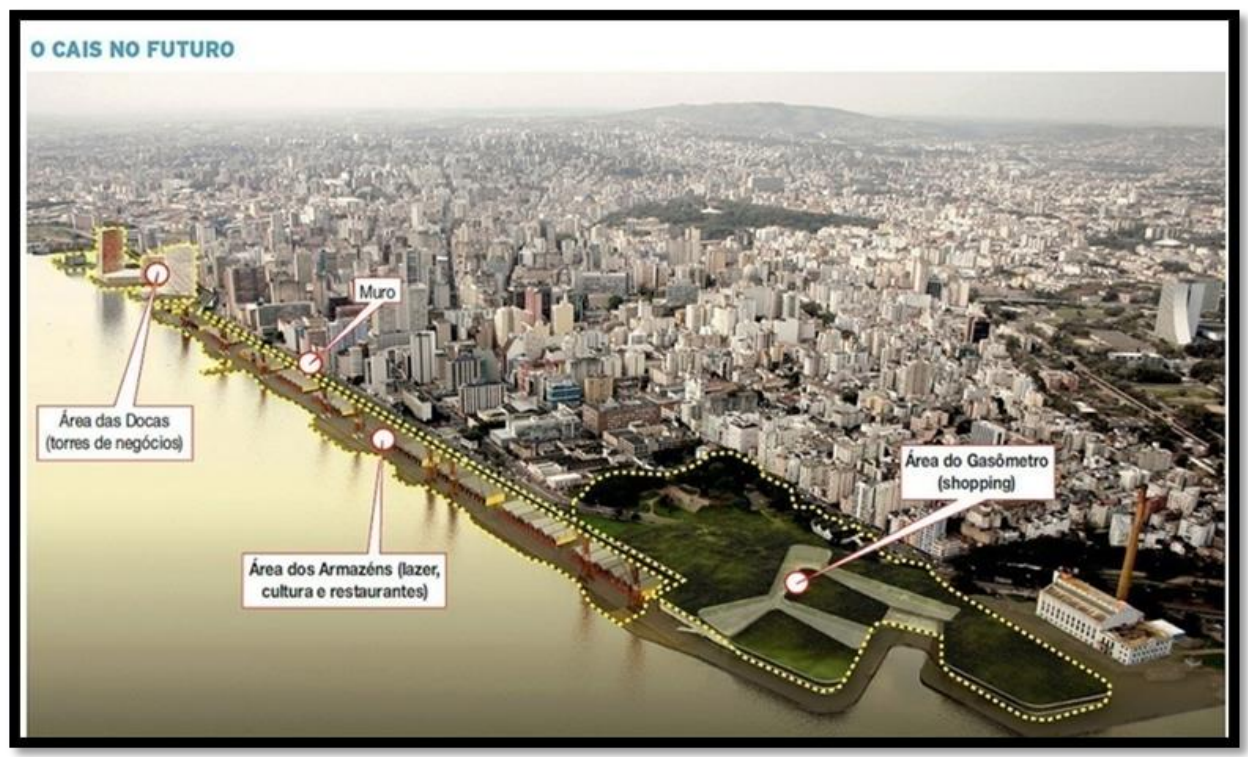

Figura 3 - Projeto de requalificação do Cais Mauá

Fonte: CAVALHEIRO (2008 apud LACERDA; MELLO, 2017). 


\section{Qual o antagonismo social? Quais os atores/agentes envolvidos com a questão?}

Buscando resistir ao projeto, surgiu o movimento "Cais Mauá de Todos" e outros movimentos que defenderam a ampla participação popular na discussão, total transparência em relação à parceria público/privada e plena legalidade do processo (da licitação e concorrência até a celebração dos contratos). 0 movimento se articula gerando significados às suas lutas e desafia os discursos hegemônicos sobre a produção do espaço (LACERDA; MELLO, 2018). 0 antagonismo social está presente na posição do Estado que surge como um elemento muito bem articulado com a iniciativa privada contra os movimentos de resistência que não concorda sobre a forma como a requalificação está sendo idealizada. Dessa maneira, o espaço se apresenta como uma verdadeira arena de lutas entre o empreendedor juntamente com o Estado e os grupos que resistem a tal movimentação.

Sobre que hegemonia urbana ele trata?

O regime de eficiência no uso do lugar que define o espaço público das cidades com a exclusiva finalidade de empresariamento urbano e gentrificação é a hegemonia urbana desafiada pelas mudanças propostas pelos ativistas contra um projeto de requalificação que pretende excluir ao invés de incluir.

Quais os discursos conflitantes?

Observou-se de um lado o discurso da eficiência que procura dar novos usos para o espaço e, colocar Porto Alegre no contexto de consumo cultural e turístico, através da política de intervenção no Cais para gerar uma imagem de cidade inovadora e integrante das tendências globais, do outro um discurso pela ampla participação popular na discussão, total transparência em relação à parceria público/privada, plena legalidade do processo e um lugar para que o gaúcho se sentisse como parte integrante.

\subsubsection{Momento 2: Ciclos}

A partir dos discursos coletados, foi possível evidenciar quatro ciclos de articulação discursiva, dois de cada lado. Dos favoráveis a requalificação, um ciclo tratou da iconização da modernidade na cidade e 0 outro por eficiência na parceria público-privada. Dos contrários, um ciclo questionava que o projeto não contempla a identidade gaúcha e o outro que o novo Cais Mauá seria um projeto elitizado. Nesses ciclos, através do apontamento das lógicas social, política e fantasmática, respondemos questões sobre como se articulam os grupos conflitantes? Quais os elementos, momentos e pontos nodais presentes? Quais deslocamentos aconteceram?

No primeiro ciclo, observou-se que a lógica social que é presente no projeto no novo Cais é a de espaço múltiplo (LACERDA; MELLO, 2018): integração da cidade com seu rio Guaíba, subordinando o uso daquele espaço a representações de vivência social e preservação da historicidade local. Há também uma 
lógica política através da disputa entre 0 arcaico e o moderno. A consequência desse embate é a descaracterização da cidade a fim de transformá-la em um não-lugar. Durante as análises foram identificadas duas cadeias de equivalências com poder de articulação na postura hegemônica que seria o poder público e a própria iniciativa privada, que fundamentam a sustentação dessa formação discursiva. Elas se articulam de tal modo que formam uma cadeia individual. No que diz respeito aos momentos e as articulações, observa-se que eles procuram criar pontos nodais com os significados ligados a acessibilidade, convivência, reintegração e consumo cultural. 0 elemento nesse caso são as empresas que fazem parte do consórcio que se articulam para formar os momentos que são as ações na tentativa de convencimento da sociedade. 0 que dá respaldo às lógicas social e políticas vigentes no novo Cais Mauá é uma lógica fantasmática pautada em um significado de "progresso" como eixo principal e alguns eixos secundários como os "benefícios" para a sociedade por meio da utilização eficiente daquele espaço, além de um ideal de "globalização" que colocar a cidade em um nível alto de desenvolvimento.

No segundo ciclo, a lógica social presente foi a de uma democracia participativa nessas parcerias entre o Estado e a sociedade, aumentando o poder de participação social (LACERDA; MELLO, 2018). A lógica política seria justamente o modo como essa democracia é alcançada por meio das articulações e lutas em busca de maiores participações populares nas decisões sobre determinado assunto público. Ou seja, a lógica política se pauta nessa relação de contestação e na interferência do mercado no governo, problematizando as funções desse executor (iniciativa privada) e desse fiscalizador (poder público). O Estado (investimento público) surge como um elemento muito bem articulado dentro da cadeia de equivalência quando é enfatizado que o mesmo terá "gasto zero" na execução da requalificação e na publicação de relatórios (momentos) que isenta o consórcio de qualquer suposta irregularidade. Verifica-se então um aliado com bastante poder que compartilha significados comuns que os torna discursivamente com laços fortes e com interesses individuais particulares. A lógica fantasmática se pauta em uma ideologia que demonstra uma gestão eficiente na condução do projeto através da parceria entre o público e o privado.

No terceiro ciclo, estava uma lógica social que remete ao enaltecimento do dia-a-dia social gaúcho, pois a questão social seria justamente a forma de convívio que um gaúcho possa ser representado perante outro, diferenciando-o de qualquer outra pessoa por meio dos seus hábitos e costumes (LACERDA; MELLO, 2018). A lógica política é por meio da própria resistência, ou seja, o jeito gaúcho de resistir se apresenta como algo interessante que particulariza essa população. E a ideologia (lógica fantasmática) se pauta em um ideal de continuidade e preservação da historicidade a fim de resgatar a sua identidade naquele projeto de requalificação no Cais Mauá. Foram identificadas oito cadeias de equivalências que fazem parte da postura contra hegemônica: 1) Cais Mauá de Todos; 2) Ocupa Cais Mauá; 3) Coletivo "A cidade que queremos"; 4) Instituto dos Arquitetos do Brasil - IAB; 5) Estudantes pela Liberdade - EPL; 6) Gabinete de Desenvolvimento 
de Assuntos Especiais - GADES; 7) Intelectuais; 8) Associação Gaúcha de Proteção ao Ambiente Natural AGAPAN (LACERDA; MELLO, 2018). Os momentos se apresentam como as ações para dificultar 0 andamento das obras, exigindo mais participação social e dentre outras coisas. A questão da identidade gaúcha surge como um argumento que sistematiza os pontos nodais inseridos no discurso.

No quarto ciclo, a lógica social presente referiu-se a um espaço compartilhado, onde toda a sociedade pode usufruir, participando e produzindo relações sociais (LACERDA; MELLO, 2018). Esse é um dos principais argumentos utilizados pelos movimentos de resistência. As lutas e forças por esse espaço compartilhado e um espaço para todos refletem uma lógica política, onde diversos atores políticos tentam gerar significados para o espaço e a lógica fantasmática reflete uma ideologia através de um protagonismo social, integrando diversas demandas e dando voz a sociedade civil.

\subsubsection{Momento 3: Intervenção}

Que nova hegemonia surgiu? O futuro do Cais Mauá permanece indefinido. Por isso o discurso continua em busca de significar aquele espaço público. Movimentos contrários continuam a questionar a postura do Estado e da iniciativa privada impedindo que as obras continuem, mas o discurso hegemônico continua a fazer parte da população gaúcha. É possível um Cais Mauá para todos? A ideia seria a possibilidade de uma integração entre estéticas. Para se pensar na Teoria do Discurso de um Cais Mauá que seja acessível, talvez só seria possível com a junção do que é considerado moderno com o arcaico.

A crítica se dá apenas em enfatizar um desses dois, pois o moderno fere com a tradição local e 0 arcaico transforma a região em lugar de passagem, ou seja, um não-lugar (LACERDA; MELLO, 2018). A proposta presente é de um tipo de integração que unifique ambos. Nesse caso, a intervenção visaria manter a identidade local, os aspectos característicos da época para que futuras gerações tenham acesso ao estilo cultural e histórico da identidade original gaúcha, toda essa questão com um toque de modernidade. Dentro desse tipo de intervenção, alguns quesitos devem ser respeitados, justamente pelas leis que discutem o tombamento do patrimônio histórico, além de que não se pode agredir de forma visual para que ele não se perca.

\subsection{A Avenida Paulista em São Paulo (SP)}

Se no caso do Cais Mauá, a política ainda está em debate e as lutas permanecem, pelo menos até o início de 2020. O caso da Avenida Paulista se mostra complementar por se tratar de uma política que se concretizou. 
Sob o principal argumento de melhorar a segurança viária a partir de novos conceitos sobre mobilidade urbana a Prefeitura de São Paulo implementou, em 2015, o Programa Ruas Abertas, com a proposta de conscientizar e estimular todos os usuários do trânsito na prática de atitudes de respeito e urbanidade no compartilhamento do espaço viário, especialmente com relação aos mais vulneráveis como pedestres e ciclistas. Entre as medidas, a abertura da icônica Avenida Paulista em datas específicas (Figura 4).

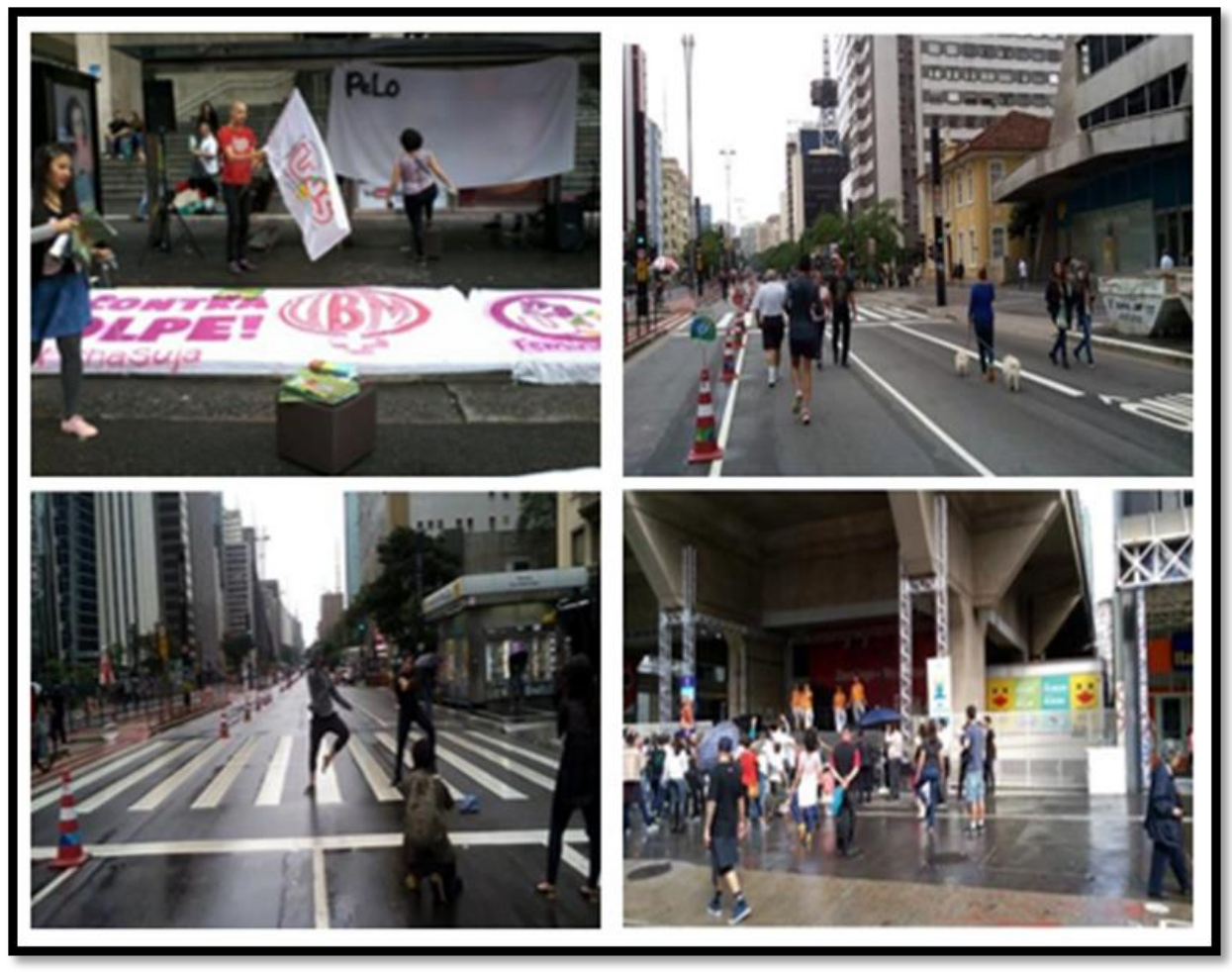

Figura 4 - Avenida Paulista Aberta

Fonte: DADOS DA PESQUISA, 2016.

A abertura da Avenida Paulista para pedestres e fechamento para veículos motorizados gerou diversos embates entre defensores e contrários da mudança (BASTOS, 2017). Embates que envolveram diferentes grupos com interesses distintos sobre o uso da Paulista e acabaram por dar novos significados àquele espaço.

\subsubsection{Momento 1: Problematização}

A principal avenida da maior cidade do Brasil é também o espelho simbólico daquela metrópole. Qualquer mudança ali envolve uma série de grupos de interesses e reflete transformações pelas quais a metrópole em geral está passando (BASTOS; MELLO, 2017a). 
Qual o antagonismo social? Quais os atores/agentes envolvidos com a questão?

Grupos a favor da política pública para abertura da avenida para uso da população e grupos contrários defendendo a manutenção da atual função de via de deslocamento daquele espaço. $O$ primeiro grupo foi formado pela Prefeitura e entidades da sociedade civil, principalmente. O segundo grupo foi formado pelo Ministério Público e por grupos de moradores da região.

Sobre que hegemonia urbana ele trata?

O regime de automobilidade que define forçosamente o espaço público das cidades para a exclusiva finalidade de deslocamento de veículos é a hegemonia urbana desafiada pelas mudanças propostas pelo Programa Ruas Abertas.

Quais os discursos conflitantes?

Após coleta de dados e informações (em sua maioria de fontes secundárias) com os atores envolvidos na disputa, observou-se de um lado o discurso da eficiência e da liberdade de ir e vir, do outro um discurso pela apropriação do espaço público pela população e seu usufruto para uma maior quantidade de pessoas (BASTOS; MELLO, 2017a).

\subsubsection{Momento 2: Ciclos}

A partir dos discursos coletados, foi possível evidenciar quatro ciclos de articulação discursiva, dois de cada lado. Dos favoráveis à política, um ciclo tratou da participação popular e o outro por vivência urbana. Dos contrários, primeiro se buscou desqualificar a gestão da prefeitura e em seguida apontar para a vocação da cidade aos fluxos. Nesses ciclos, através do apontamento das lógicas social, política e fantasmática, respondemos questões sobre como se articulam os grupos conflitantes? Quais os elementos, momentos e pontos nodais presentes? Quais deslocamentos aconteceram?

No primeiro ciclo, observou-se que a lógica social que vigora na Paulista é a de espaço para a automobilidade, para os fluxos, para os negócios (BASTOS; MELLO, 2017a). Tendo em vista que, no passado, projetos também tentaram transformar a Paulista e fracassaram, há também uma lógica política que costuma ser inflexível às mudanças na via. As articulações que ilustram tal lógica podem ser visualizadas na cadeia de equivalência formada entre os elementos como a Ordem dos Advogados do Brasil (OAB-SP), a Associação Paulista Viva, o Rotary Club, representantes dos moradores e o Promotoria de Justiça (PJHURB) que se posicionaram contra a medida de abertura da Paulista para pedestres. Os primeiros defendendo os interesses do tráfego, do comércio e dos moradores da região, e o último atendendo o pleito dos demais e questionando a Prefeitura sobre a medida. 
Entre os momentos que estes elementos se articularam, podemos citar: o uso de legislação prévia (TAC) que garantia apenas três interdições anuais na avenida, para coibir a medida; o deslocamento por parte dos elementos contrários que param de tentar coibir a medida e propõem a alternativa de fechamento apenas parcial; a apropriação dos discursos de "defesa do direito de ir e vir" na avenida e de "defesa ao comércio" da região como pontos nodais de tal articulação; e tentativas de esvaziar significados defendidos pelos grupos favoráveis à abertura como "espaço democrático" e "cidade humana", os assimilando em seus próprios discursos. $\mathrm{O}$ que dá respaldo às lógicas social e políticas vigentes na Paulista é uma lógica fantasmática pautada por conceitos de velocidade, de consumo, de liberdade e de individualidade oriundas da modernidade, que coadunam com a teoria econômica vigente: o neoliberalismo.

No segundo ciclo, a lógica social presente foi a de local de contestação, a Avenida já tinha histórico de ser um espaço para manifestação, de ser a ágora da metrópole (BASTOS; MELLO, 2017a). Contudo, aquele espaço era visto apenas como meio, e não como fim. E seria com esse deslocamento que a sociedade civil percebeu que podia transformar a Avenida ao dar-lhe novos usos. Assim, a participação popular nas decisões sobre a Paulista buscou mostrar ou reafirmar que aquele espaço é público e por isso sua gestão envolveria toda a população da cidade e não apenas os moradores. A lógica política que movimentou tal posicionamento pode ser dividida em quatro atos. Ela se inicia com a geração de novos significados para aquele espaço. O segundo ato foi o convencimento à Prefeitura, uma cadeia de equivalência entre governo e grupos favoráveis se forma. $O$ terceiro ato foi a desmistificação dos argumentos dos grupos contrários. O último ato foi garantir a continuidade da medida. A lógica fantasmática presente aqui é uma busca por protagonismo social. Ou seja, os grupos favoráveis à abertura da Paulista querem ser posicionados como agentes políticos de relevância nos debates sobre o uso urbano da cidade.

No terceiro ciclo, estava uma lógica social de ordenamento urbano (BASTOS; MELLO, 2017a). Ou seja, que a Prefeitura só deveria fazer mudanças que comprovadamente gerassem resultados positivos para aquele espaço e que fossem aprovadas pelos principais envolvidos na questão. $E$ com isso, novas experiências, como a abertura da Paulista, deveriam ser melhor avaliadas. A lógica política que foi observada para os elementos contrários defenderem seus pontos de vista, apareceu em três momentos distintos: (1) tentar desqualificar a medida; (2) apontar a falta de diálogo para sua implementação; e (3) e questionar a gestão da Prefeitura como um todo. A lógica fantasmática que parece se apresentar nas lógicas políticas e sociais apontadas é a de apropriação de um espaço público por uma camada da população que lá habita e que vê aquele lugar como uma propriedade privada.

No quarto ciclo, a lógica social presente referiu-se ao espaço público com múltiplas funções, como lugar de encontro, de vivência e na escala humana (BASTOS; MELLO, 2017a). Seus defensores lutavam por tornar a metrópole paulistana mais humana, com seus espaços públicos resgatando a função social de lugar 
de encontro e que possam ser geridos por toda a população. A lógica política que vigorou foi a articulação para a apropriação da Avenida Paulista, de forma a criar um imaginário na população que tal espaço poderia ter outros fins e não somente a circulação de veículos e aproveitar as oportunidades que a agenda de governo da Prefeitura proporcionava. A lógica fantasmática que coaduna com essas visões é a de um novo urbanismo pautado pela ideia de Cidade para Pessoas. Mais especificamente, é busca de conceitos, como cidadania e coletividade, que foram sendo perdidos com a emergência da cidade maquínica na modernidade.

\subsubsection{Momento 3: Intervenção}

Que nova hegemonia surgiu? A abertura da Paulista continua. Posicionamentos a favor e contra continuaram a aparecer. No início de 2016, as entidades da sociedade civil Minha Sampa, Cidade Ativa e SampaPé, lançaram uma iniciativa virtual para ouvir a sociedade e orientar a criação de um Projeto de Lei colaborativo para regulamentar o uso de ruas abertas em toda a cidade, incluindo a Avenida Paulista. Finalmente, em junho de 2016, a Abertura da Paulista tornou-se uma política pública. A Prefeitura publicou 0 Decreto 57.086, instituindo o Programa Ruas Abertas, nos termos da Política Nacional de Mobilidade Urbana (BASTOS; MELLO, 2017b). O que se oficializaria em dezembro de 2016, com o prefeito assinando a Lei 16.607/2016 para instituir o programa.

Se um paradigma urbano precisa ser quebrado para outro emergir, a violência para tal não pode ser abrupta, mas precisa ser significativa. Política e tecnicamente, fechar ruas temporariamente para o tráfego de veículos automotores é uma medida de fácil reversão. Simbolicamente, é uma medida que favorece a propagação de novos significados desejados (como convívio, civilidade e apropriação do espaço pela população) por seus defensores e que desafiam àqueles presentes na hegemonia urbana (como individualidade, velocidade, ordenamento). E se a ideia é gerar um imaginário na população de uma nova hegemonia urbana, a Avenida Paulista como lugar símbolo da cidade era ideal (BASTOS, 2017). Ali, a medida receberia mais atenção da imprensa e por consequência seria mais difundida na população.

\section{CONSIDERAÇÕES FINAIS}

A discussão sobre cidades, o espaço, o lugar, os problemas urbanos, o direito à cidade e a produção no espaço urbano têm se mostrado relevante para a realidade das cidades brasileiras, se apresentando como um grande desafio na atualidade para os gestores, pois é uma realidade que bate em nossa porta diariamente: poluição, trânsito caótico, violência, desemprego, transporte público, especulação imobiliária, favelização, mobilidade e dentre outros. 
O objetivo do referido texto foi de propor um delineamento metodológico com base na Teoria do Discurso de Laclau e Mouffe (2015) para análise de transformações urbanas na administração pública. Para isso foi apresentado duas pesquisas em que o delineamento metodológico foi utilizado. 0 primeiro tratou das lutas por ressignificação do Cais Mauá no Rio Grande do Sul e o segundo sobre as disputas por diferentes grupos pelo uso da Avenida Paulista em São Paulo.

O modelo metodológico se apresentou como adequado, pois foi possível identificar os argumentos, bem como os atores e as formas de articulação que os grupos estavam envolvidos, compreendendo uma análise social e política que procura demonstrar como e porque uns discursos prevalecem em relação a outros.

Tanto o Cais Mauá, como a Avenida Paulista representam problematizações sobre ressignificações urbanas. Os exemplos discutidos aparecem apenas como uma fração desse discurso maior sobre a questão da mobilidade urbana, a privatização de espaços públicos, urbanismo crítico, planejamento urbano, 0 potencial dano ao patrimônio cultural, uso eficiente do espaço, engajamento político e na participação popular. O novo Cais e o Programa Ruas Abertas na Paulista estão longe de ser consenso naquelas realidades. Na Avenida Paulista, embora a política tenha se concretizado, não é incomum que eventos, como o Exame Nacional do Ensino Médio, causem a sua interrupção. Já as lutas no Cais Mauá não tem previsão de término e o futuro permanece indefinido. Ou seja, são espaços onde o significante vazio é precário e serve como ponto de passagem, pois as forças políticas presentes seguem se reorganizando e continuam na busca de novos significados.

Esse trabalho pretende contribuir para o campo que discute a produção do espaço a partir de suas dinâmicas, compreendendo a atuação dos diferentes atores políticos na perspectiva da Teoria do Discurso de Laclau e Mouffe. As discussões aqui apresentadas refletem sobre o modo de organização e articulação da sociedade civil e como seu poder de coletividade pode chegar a uma suposta hegemonia. Indo mais além, como o próprio Laclau discute por meio de uma democracia plural e radical. Como reflexões secundárias, essas questões podem gerar contribuições sobre o planejamento nas cidades e a eficiência econômica do espaço através de equipamentos urbanos sob o ponto de vista discursivo. Nesse caso, é interessante discutir políticas públicas com a participação social para que o espaço público seja concebido de forma democrático, coletivo e social.

Sugere-se que a teoria-método utilizada neste trabalho seja aplicado em outras realidades, como também a comparação dos resultados com outros contextos, além de investigações semelhantes a esta em relação a outros projetos de modificações em espaços públicos que poderiam contribuir para um aprofundamento da discussão aqui apresentada. 


\section{REFERÊNCIAS}

BACCHI, C. Why Study Problematizations? Making Politics Visible. Open Journal of Political Science. v. 2. n. 1, p. 1-8, 2012.

BASTOS, Antonio Fagner da Silva. Avenida Paulista das pessoas: disputas pela ressignificação do espaço público de uma metrópole. 2017. Dissertação de Mestrado. Universidade Federal de Pernambuco.

BASTOS, A. F. S.; MELLO, S. C. B. Paulista aberta: significados da avenida símbolo da cidade de São Paulo. URBANA: Revista Eletrônica Do Centro Interdisciplinar De Estudos Sobre a Cidade, v. 9, n. 3, p. 521-539, 2017a.

BASTOS, A. F. S.; MELLO, S. C. B. Criando Espaços de Lazer: As Lutas Políticas pela Ressignificação da Avenida Paulista. PODIUM Sport, Leisure and Tourism Review, v. 6, n. 1, p. 43-61, 2017b.

CAVALHEIRO, M. H. Manifesto Mauá: uma costura urbana no centro de Porto Alegre. Trabalho de Conclusão de Curso - TCC. (Curso de Arquitetura e Urbanismo). Universidade Federal do Rio Grande do Sul. Faculdade de Arquitetura. Porto Alegre: 0 autor, 2008.

CORDEIRO, A. T.; MELLO, S. C. B. Teoria do discurso laclauniana: uma mediação entre teoria crítica e prática política. Anais do Encontro Nacional da Anpad, Rio de Janeiro, RJ, Brasil, 2010.

DELLAGNELO, E. H. L.; BÖHM, S.; MENDONÇA, P. M. E. Organizing resistance movements: contribution of the political discourse theory. Revista de Administração de Empresas, v. 54, n. 2, p. 141-153, 2014.

FOUCAULT, M. A ordem do discurso. São Paulo: Loyola, 1996.

GLYNOS, J.; KLIMECKI, R.; WILLMOTT, H. Logics in policy and practice: a critical nodal analysis of the UK banking reform process. Critical Policy Studies, 171, 123, 2015.

GLYNOS, J.; HOWARTH, D. Logics of Critical Explanation in Social and Political Theory. London/New York: Routledge, 2007.

HOWARTH, D. Discourse. New York: Open University Press: McGraw Hill, 2000.

HOWARTH, D; STAVRAKAKIS, Y. Introducing

Discourse Theory and Political Analysis. In: HOWARTH, D; NORVAL, A.J; STAVRAKAKIS, Y.
Discourse theory and political analysis. Manchester: Manchester University Press, 2000.

HOWARTH, D. R. Poststructuralism and After: Structure, Subjectivity and Power. Palgrave Macmillan: UK, 2013.

HOWARTH, D.; GLYNOS, J.; GRIGGS, S. Discourse, explanation and critique. Critical Policy Studies, 10(1), 99-104, 2016.

LACERDA, Carlos César de Oliveira. Se esse Cais fosse meu: gestão do espaço urbano e a luta pela significação entre discursos e [R] existência. 2017. Dissertação de Mestrado. Universidade Federal de Pernambuco.

LACERDA, C. C. O; MELLO, S. C. B. O direito à cidade e a produção do espaço entre discursos: a luta pela significação na "recuperação" de ambientes urbanos. urbe. Revista Brasileira de Gestão Urbana, v. 9, n. 3, p. 543-558, 2017.

LACERDA, C. C. O; MELLO, S. C. B. Do velho Cais Mauá a novos negócios: conflitos inerentes a representação política da identidade na gestão do espaço urbano. Revista Brasileira de Planejamento e Desenvolvimento, v. 7, n. 2, p. 339-361, 2018.

LACLAU, E.; MOUFFE, C. Hegemony and Socialist Strategy: Toward a radical Democratic Politics. London: Verso, 1985.

LACLAU, E.; MOUFFE, C. Hegemonia e estratégia socialista: Por uma política democrática radical. São Paulo: Intermeios, 2015.

LOPES, A. C.; MENDONÇA, D.; BURITY, J. A. A contribuição de Hegemonia e estratégia socialista para as ciências humanas e sociais. In: LACLAU, E.; MOUFFE, C. Hegemonia e estratégia socialista: Por uma política democrática radical. São Paulo: Intermeios, 2015.

MENDONÇA, D. A noção de antagonismo na Ciência Política contemporânea: uma análise a partir da perspectiva da teoria do discurso. Revista de Sociologia e Política, Curitiba, n. 20, p. 135-145, 2003.

MENDONÇA, D. Como olhar "o político" a partir da teoria do discurso. Revista Brasileira de Ciência Política, v. 1, p. 153, 2009.

MENDONÇA, D. A teoria da hegemonia de Ernesto Laclau e a análise política brasileira. Ciências Sociais Unisinos, v. 43, n. 3, p.249-258, set./dez. 2007. 
MENDONÇA, D. Antagonismo como identificação política. Revista Brasileira de Ciência Política, Brasília, n. 9, p. 205-228, set./dez. 2012.

OLIVEIRA, G. G.; OLIVEIRA, A. L.; MESQUITA, R. G. A Teoria do Discurso de Laclau e Mouffe e a Pesquisa em Educação. Educação\&Realidade, Porto Alegre, v. 38 , n. 4, p. 1327-

1349, out./dez. 2013.

SILVA, C. C. G.; BATISTA, M. M.; MELLO, S. C. B. A Teoria do Discurso de Laclau e Mouffe. In: MELLO, S. C. B. (Org.). Construção Social da Tecnologia e Teoria do Discurso. Recife: Editora UFPE, 2014

TORFING, J. New theories of discourse: Laclau Mouffe, and Zizek. Oxford: Blackwell. 1999. 